\title{
Book Review: Weaving Success: Voices of Change in African Higher Education
}

\author{
By Megan Lindow. \\ New York: Institute of International Education, 2012. 224 pp. \\ ISBN: 978-0-87206-342-6.
}

\begin{abstract}
Foregrounding success in Africa is an important strategy in the process of positioning the continent as a viable player in the twenty-first century. Although attempts to do so do not negate the continent's challenges, they do allow conversations that contextualize these challenges as opportunities for development and innovation. Weaving Success: Voices of Change in African Higher Education shares stories from selected universities in nine African countries-Egypt, Ghana, Kenya, Madagascar, Mozambique, Nigeria, South Africa, Tanzania, and Uganda. These universities all received funding from the Partnership for Higher Education in Africa (referred to as the "Partnership"), which is a collaboration of seven major US foundations. Recognizing that sustainable African development is likely to be linked to the development of African higher education, the Partnership committed to supporting several African higher education initiatives and projects. In Weaving Success, Megan Lindow provides a visually and conceptually rich account of some of these successes, which could be a potentially valuable part of the strategy to reposition Africa (and African higher education) globally.

The style of the book is descriptive and conversational and purports to give expression to the stories of "individuals whose visions and actions have, collectively and in diverse ways, spurred transformation at universities in Africa” (2). Lindow's accessible and rich style makes use of multiple "voices" and photographs of people working in, working alongside, and learning in African higher education. Readers are likely to connect with the narratives and may be left with a strong and positive sense of the people behind them. As identified by Njabulo Ndebele in the book's foreword, government and business leaders/policy makers who engage with the book are likely to be inspired toward future collaboration with African higher education. In this regard, it is possible that the stories in the book will provide policy makers and leaders with the confidence to initiate and maintain further waves of research and socio-economic development with a distinct African higher education flavor.
\end{abstract}

The book's major theme, which appears to center on the interdependent relationship between socioeconomics and higher education transformation, is strongly aligned to Manuel Castell's notion of universities "as important drivers for development" (29). This theme reinforces the potential role that academics in African higher education can play toward African development and the Millennium Development Goals. In particular, examples of African responses to poverty, food insecurity, education, gender equality, and environmental sustainability are revisited in the multiple accounts of contemporary teaching, learning, and research in African higher education. The author uses the metaphor of a woven cloth to tie the book chapters together, and this metaphor certainly works well in facilitating a coherent read.

The foreword and first three introductory chapters orient the reader to the context of Africa, African higher education, and global socio-economic development imperatives. In setting the stage for the African context, Lindow highlights the major political, human rights and development challenges that the nine relevant African countries have encountered. Differences between these countries are carefully identified then woven together through the abovementioned imperatives and challenges. Although the book claims to focus on "the perspectives of individuals at African universities” (27), inevitably this book is also a report on the Partnership and their recent collective investment of US\$440 million in African higher education. The introductory chapters of the book also identify African higher education as being "caught in a triangle” (5) of access, financing, and quality, which inevitably constrain growth. A path toward freedom from this constraining triangle is introduced in Chapter 12 where long-term financial sustainability within African higher education is explored.

The core of the book highlights examples from the Partnership's primary areas of focus, which include strengthening information and communication technology and supporting research and advocacy initiatives in African higher education. In addition to these areas of focus, research, teaching, advocacy, and development are reported on as well. Chapter 4 focuses on 
innovations in e-learning across a variety of African countries. Examples of technological advances such as a laptop scheme for lecturers, online laboratories, and the use of radio, MP3 and mobile phones are provided and linked to the enhancement of teaching and learning in rural parts of the continent. One particularly empowering example of innovation includes the provision of e-learning to women in the Marsabit District in Kenya. In a district where access to education for women and girls is constrained by socioeconomic circumstances, e-learning programs aimed at increasing female participation in education have been critical. Chapter 5 is focused on specific projects aimed at addressing deficits in basic operational needs at some of the African higher education institutions (HEIs). Examples of these include physical infrastructure and digitization developments in the libraries of multiple African universities and specific campus improvement projects such as sustainable solutions to electricity and water shortages at the University of Jos in Nigeria.

In addition to an overview of Partnership funding aimed at addressing basic operational needs in various African HEIs, the mid to latter parts of the book also describe important higher education issues of academic freedom, innovative research, networking, and sustainability and how they are playing out in African higher education. Chapter 6 highlights the interplay between human rights, socio-political change, and academic freedom in Egypt and South Africa. Through the voices of various actors in Egyptian and South African higher education, Lindow tracks the complex relationship between government, higher education, democracy, and academic freedom. Issues of gender equity in African higher education are highlighted in Chapter 7. This chapter provides instances where participation in higher education by female academics, administrators, and students has been promoted. In particular, Partnership funding in the form of the Female Scholarships Initiative appears to have contributed to enhancing gender equity in HEIs in Uganda, Tanzania, and South Africa. Strategies to bolster gender equity in science, engineering, and technology are ongoing, an example of such a strategy being the Undergraduate Women's Scholarship Programme in South Africa. This program targeted a select group of female students from educationally disadvantaged backgrounds who, with the assistance of funding, were able to access higher education studies in science, engineering, and technology.

Linking back to Manuel Castells’ notion of higher education as a driver of development, Chapters 9 and 10 explore examples of high quality African research that is innovative and responsive to poverty, health, and the socio-economic development needs on the continent. Despite resource constraints and difficult living/working conditions, it is indicated that it is these very constraints and adverse living/working conditions that can ignite ground-breaking research and responses to socio-economic problems. An example of this is the Makapad, "an inexpensive, locally-sourced, and environmentally sustainable sanitary pad created to keep poor adolescent girls from missing school during” (168) menstruation. Developed by an engineering lecturer at Makerere University in Uganda, the Makapad is an illustration of the way in which gender empowerment, higher education research and technology, and product sustainability in the market/context can interplay.

Sustainability of African higher education is indirectly introduced in Chapter 8, while Chapter 12 specifically focuses on financial sustainability. Strategies to induct a new generation of academics are discussed, and international collaboration and support and mentoring programs aimed at young academics are described. Funding strategies for such sustainability centralize around managing and securing alumni support, the efforts of which for selected South African HEIs are the focus for the bulk of this chapter.

The strength of Weaving Success is its readability and vivid narratives of achievements in African higher education over the past decade. It conveys a transformative message-one that is underpinned by rich accounts of potential, energy, innovation, and hope. In addition, the book is broad in scope, yet also offers sufficient detail to enable the reader to meaningfully engage with the stories. However, the book is not without its limitations, perhaps the most notable one being a discussion on the ethical aspects of the research being reported on. For example, Lindow describes a research project involving three Ugandan primary schools that looked at the relationship between English language development programs and the development of basic infrastructure, mainly the provision of clean water and toilets (164). Findings from the three schools, which offer different levels of basic provisions, emphasize that a successful English language program is not contingent on basic provisions such as clean water and toilets. I wondered whether this finding warranted the apparent delay of basic infrastructure developments in two of the primary schools involved in the study. In order to clarify my concern around the research ethics of this project, I attempted to search for more information about this project on the relevant funder and university websites. The search was unsuccessful. As a result, it may be difficult for readers to follow up on the ethical and other aspects of research projects of interest to them.

Weaving Success' overarching power lies in its metaphoric integration of multiple and varied stories of success, innovation, hope, and sustainability in African higher education. As a higher education teacher and researcher in Africa, I was reminded about the strong relationship between the development of African higher education and African transformation. Lindow's work aligns 
Africa as a central player in twenty-first century responses to the challenges of poverty, food insecurity, and socio-economic transformation.

Reviewed by Nicholas Munro University of KwaZulu-Natal, South Africa 